\title{
A Note Study on Antidiabetic Effect of Main Molecules Contained in Clove Using Molecular Modeling Interactions with DPP-4 Enzyme
}

\author{
Bouchentouf Salim $^{1,2, *}$, Ghalem Said ${ }^{2,3}$, Missoum Noureddine ${ }^{2,3}$, Allali Hocine ${ }^{2,3}$, \\ Bouchentouf Amina Angelika ${ }^{4}$ \\ ${ }^{1}$ Faculty of Technology, Doctor Tahar Moulay University, Saida, Algeria \\ ${ }^{2}$ Laboratory of Naturals Products and Bioactives, Tlemcen, Algeria \\ ${ }^{3}$ Department of Chemistry, Faculty of Sciences, Aboubekr Belkaid University, Tlemcen, Algeria \\ ${ }^{4}$ Department of Mathematics, Faculty of Sciences, Djillali Liabes University, Sidi Bel Abbes, Algeria
}

Email address:

bouchentouf.salim@yahoo.fr (B. Salim), salim.bouchentouf@univ-saida.dz (B. Salim)

${ }^{*}$ Corresponding author

\section{To cite this article:}

Bouchentouf Salim, Ghalem Said, Missoum Noureddine, Allali Hocine, Bouchentouf Amina Angelika. A Note Study on Antidiabetic Effect of Main Molecules Contained in Clove Using Molecular Modeling Interactions with DPP-4 Enzyme. International Journal of Computational and Theoretical Chemistry. Vol. 5, No. 1, 2017, pp. 9-13. doi: 10.11648/j.ijctc.20170501.12

Received: February 24, 2017; Accepted: March 20, 2017; Published: April 13, 2017

\begin{abstract}
Clove (Syzygium aromaticum) is precious spice used over the world in cuisine and medical treatment. Essential clove oil contains many bioactive molecules which have therapeutic interest. In this work we study interactions of DPP-4 enzyme (responsible of diabetes type 2) with main molecules contained in clove essential oil using molecular mechanic, molecular dynamics and molecular docking (method which predicts the preferred orientation of one molecule to a second when bound to each other to form a stable complex). Molecular Operating Environment software was used. The obtained results show that Acetyleugenol molecule is the best inhibitor of DPP-4 enzyme according to score energy. As a conclusion we can say that clove has a significant influence on diabetes treatment.
\end{abstract}

Keywords: Diabetes Type 2 (T2DM), Clove, DPP-4, MOE (Molecular Operating Environment)

\section{Introduction}

Clove (Syzygium aromaticum or Eugenia cariophylata) a precious and remarkable spice, an aromatic herb used for centuries in Orient, Asian and African cuisine, it is a nailshaped dried flower bud belonging to Myrtaceae families. This extraordinary spice is originated from Mollucas Islands in Indonesia. Nowadays, the larger producer countries of clove are Indonesia, India, Malaysia, Sri Lanka, Madagascar and Tanzania specially the Zanzibar Island $[1,2]$.

Clove is a prominent and remarkable medicinal plant owing to the large spectrum of pharmacological effects. Among thousands other spices, this valuable spice attracted the attention of many researchers due to the powerful antioxidant and antimicrobial activities.

The essential oil of clove has been widely used as spice and is well known for its medicinal properties. It is active against oral bacteria associated and fungi [3]. Previous studies also have reported antifungal [4-6], antioxidant [7-9], antibacterial [10-12, 17], and anti-inflammatory [3-14] properties of clove oil.

The discovery of type 2 diabetes (T2DM) is common in ambulatory medicine; the increasingly growing epidemic is linked to a reduced life expectancy, obesity, lack of physical activity, and due to an unbalanced diet particularly rich in fats and refined sugars [16]. This disease has a significant genetic and frequently associated predisposition to obesity, hypertension and dyslipidemia [17].

Type 2 diabetes is a metabolic disease characterized by chronic hyperglycaemia with pathophysiological factors 
including increased resistance in peripheral tissues (liver, muscle) to the action of insulin, insufficient insulin secretion from $\beta$-cells in pancreas, inappropriate glucagon secretion, and a decrease in the effect of incretins, gut hormones stimulating postprandial insulin secretion [18].

Clove oil reportedly modulated physiological responses in streptozotocin-induced diabetic rats [19]. Food seasoning spice mixtures improved glucose metabolism and lipid profile in fructosefed hyperinsulinemic male Wistar rats [20]. The reduced plasma glucose and insulin levels, together with the favourable lipid profile, were possibly brought about through improved insulin-sensitising actions of the active constituents. The spices improved the biomarkers of oxidative stress in the tissues of fructose-fed insulin-resistant rats [21]. Culinary, herb and spice extracts also inhibited protein glycation in vitro and the most potent inhibitors were extracts of cloves, ground Jamaican allspice, and cinnamon [22]. Insulin-like biological activity of clove and other culinary or medicinal plant aqueous extracts were also proven in vitro [23].

Studies show that dietary supplementation with cloves significantly reduced blood sugar increases and lipid peroxidation in diabetic rats and restored the antioxidant enzyme levels. Dietary cloves also reduced tissue injuries in the lens, cardiac muscles, and livers of these rats. Clove oil was emphasized to adjust physiological responses in streptozotocin-induced diabetic rats [24]. Studied the effects of cloves on some target organs of Streptozotocin (Nethylnitrosocarbamoyl- D-glucosamine) induce Oxidative stressed diabetic rats. Dipeptidyl-peptidase (DPP-4), which is also known as CD26 or 5TB4 is a ubiquitously expressed glycoprotein of $110 \mathrm{kDa}$, which was first characterized by Hopsu-Havu and Glenner. DPP-4 is a type II transmembrane protein, which is also cleaved off the membrane and released into the circulation by a process called shedding. The importance of DPP-4 for the scientific and medical community raised substantially since the approval of DPP-4 inhibitors for the treatment of type 2 diabetes mellitus (T2DM). These so-called gliptins increase the incretin levels and therefore prolong the post-prandial insulin action. Since soluble DPP-4 is characterized as an adipokine and also correlates with parameters of the metabolic syndrome, it might also be an important molecular biomarker. DPP4 is a multifunctional enzyme, which serves as a binding partner for numerous peptides, among which are adenosine deaminase (ADA) and extracellular matrix proteins. Moreover, as a serine protease, DPP-4 cleaves numerous substrates, which further amplifies its complexity of action. Thus, DPP-4 is involved in signaling processes, immune cell activation, and its dysregulated expression and release is associated with numerous diseases [25].

This paper highlights anti-diabetic effect of clove's chemical compounds by studying different interactions of DPP-4 enzyme and clove's molecules using molecular docking.

\section{Materials and Methods}

\subsection{Clove Main Compounds}

The main chemical compounds of clove are: Eugenol, alpha-humulen, Beta-Caryophyllene, Acetyleugenol, caryophyllene oxide [26].

\subsection{Preparation and Optimization of Both Enzyme and Clove Main Compounds}

Download of Dipeptidyl-peptidase (DPP-4) was done from PROTEIN DATA BANK (code 5T4B) with threedimensional structure obtained by X-ray diffraction (resolution 1.76 Å) (Figure 1). Eugenol, alpha-humulen, Beta-Caryophyllene, Acetyleugenol, caryophyllene oxide were downloading from PubChem data base. Using MOE software (Molecular operating environment), we select the active site in the enzyme and we minimize the energy of both enzyme and molecules. Energy minimizing was done under following conditions: Temperature $=300^{\circ} \mathrm{K}, \mathrm{pH}=7$, the geometry was performed using the field strengths in the MMFF94x implanted in MOE, and Hamiltonian AM1. Figure 2 shows the active site of the enzyme with molecule of co-crystallization.

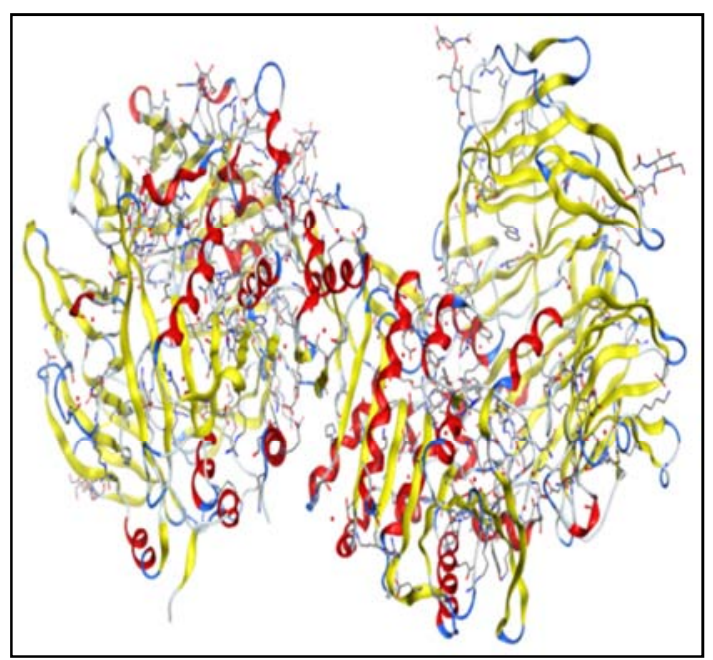

Figure 1. 3D enzyme DPP-4 (5T4B).

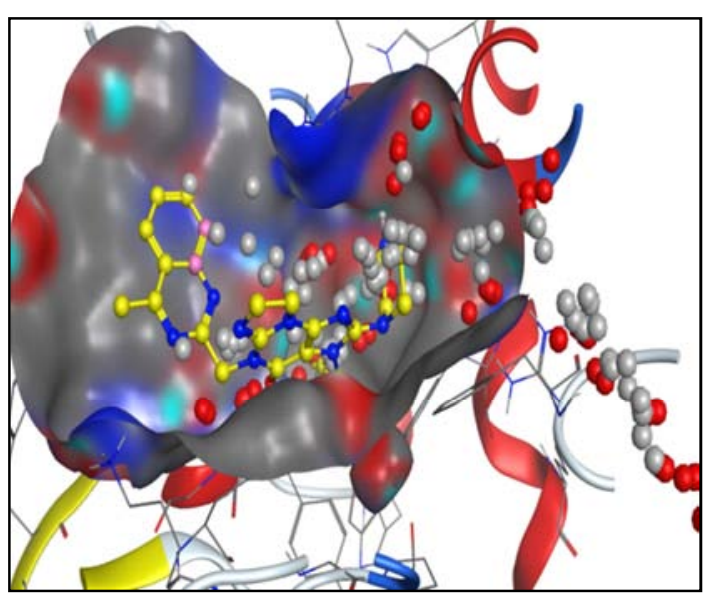

Figure 2. Active site enzyme isolated. 
The active site was performed using MOE site finder. The MOE site finder first calculates a collection of alpha spheres. The collection of alpha spheres is pruned by eliminating those that correspond to inaccessible regions of the receptor as well as those that are too exposed to solvent. Only the spheres that correspond to locations of tight atomic packing in the receptor are retained. Next, each alpha sphere is classified as either "hydrophobic" or "hydrophilic" depending on whether the sphere is in a good hydrogen bonding spot in the receptor. Hydrophilic spheres not near a hydrophobic sphere are eliminated (since these generally correspond to water sites). The alpha spheres are then clustered using a single-linkage clustering algorithm to produce a collection of sites. Each site consists of several alpha spheres at least one of which is hydrophobic. Only clusters above a minimum size, both in terms of the number of spheres and the geometric extent, are retained. Finally the sites are ranked according to the number of hydrophobic contacts made with the receptor, i.e. the number of hydrophobic atoms within a contact distance of any of the retained alpha spheres. Table 1 shows for each site in DPP-4 enzyme the size (in receptor atoms), the number of hydrophobic contacts and the number of sidechain contacts are reported a long with a list of residues containing the contacting atoms [27].

Table 1. DPP-4 active site size description (visible only).

\begin{tabular}{llllll}
\hline Site & Size & PLB & Hyd & Side & Residues \\
\hline 1 & 11 & 1.00 & 7 & 20 & $1:($ ARG125 TRP201 GLU205 ASN710 HIS740 GLY741)2:(75N810) \\
2 & 14 & 1.00 & 8 & 11 & $1:($ TYR631 TRP659 TYR666) \\
\hline
\end{tabular}

\subsection{Docking and Building Complexes}

After optimization of both molecules ligands and enzyme, we proceed to positioning of ligands in to active site of the enzyme (5T4B) using Dock module (Molecular Docking) with MOE software (Molecular operating environment). The purpose of the Dock application is looking at favorable conformational binding between medium size ligands and a not so soft macromolecular target, which is usually a protein [26]. For each ligand, a number of conformations called poses were generated.

\section{Results and Discussion}

Table 2. Energy balance of 5 complexes (Kcal/mol).

\begin{tabular}{llllllll}
\hline MOLECULE & POSES & S & Rmsd_refine & E_conf & E_place & E_score1 & E_refine \\
\hline Eugenol & 10 & -4.69787455 & 2.13531995 & 30.1368256 & -51.8319969 & -9.50648785 & -10.9069853 \\
Acetyleugenol & 9 & -5.1175704 & 1.44166493 & 46.3503304 & -41.7488823 & -9.48483753 & -14.8497696 \\
Alpha-Humulene & 5 & -4.59825325 & 1.83373678 & 63.35252 & -37.9288902 & -7.93170071 & -11.8100414 \\
Beta-Caryophyllene & 7 & -4.56311417 & 1.40489578 & 63.2073822 & -33.0641327 & -8.03918076 & -6.62489271 \\
Caryophyllene Oxide & 6 & -4.52105761 & 1.19785535 & 55.7170753 & -20.6118526 & -8.78948498 & -5.56917048 \\
\hline
\end{tabular}

S: the final score; is the score of the last step (energy of the complex), rmsd refine: the mean square deviation between the laying before refinement and after refinement pose, E_conf: energy conformer, E_place: score of the placement phase, E_scor1: score the first step of notation, E_refine: score refinement step and number of conformations generated by ligand, poses: Number of conformations.

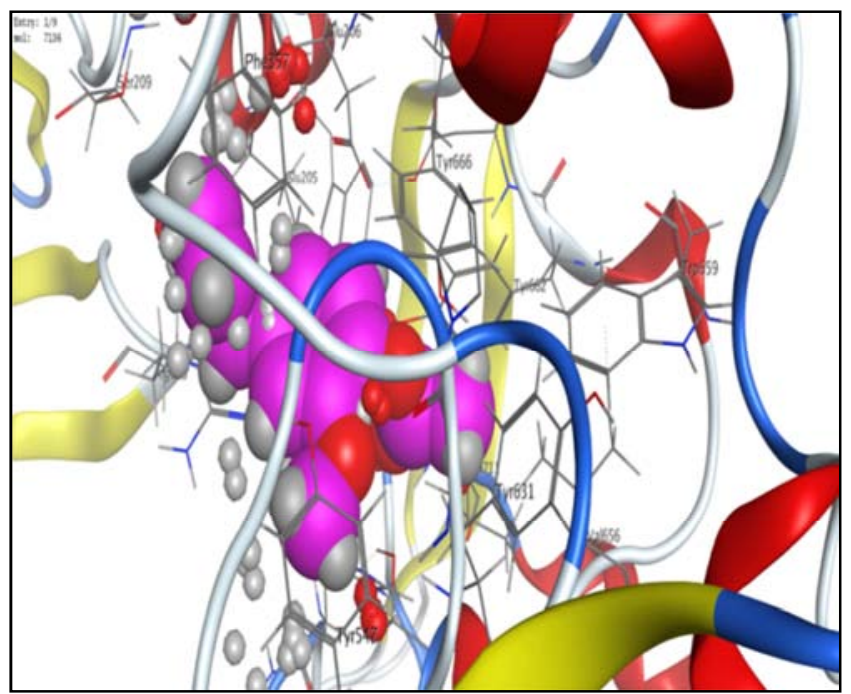

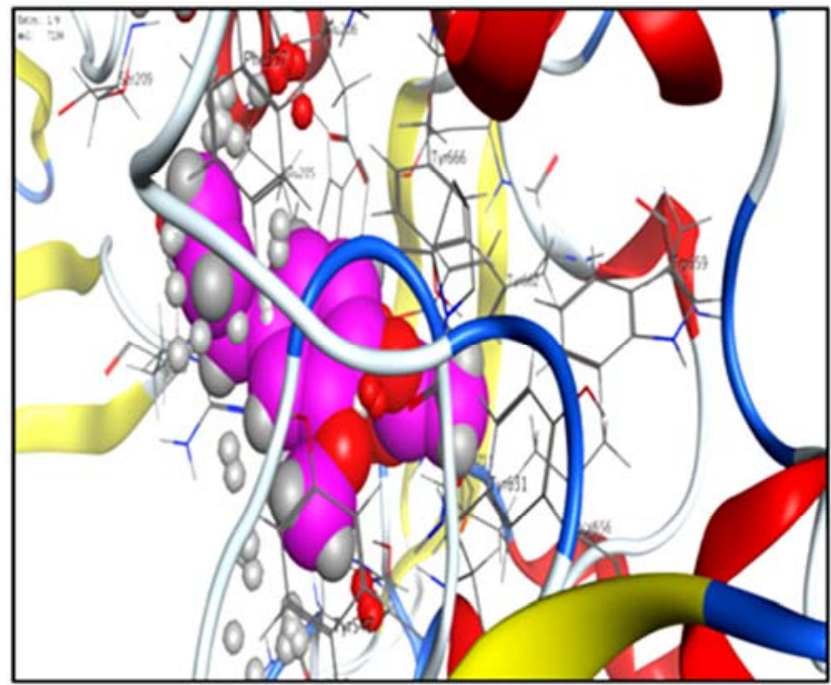

$3 \mathrm{D}$ 


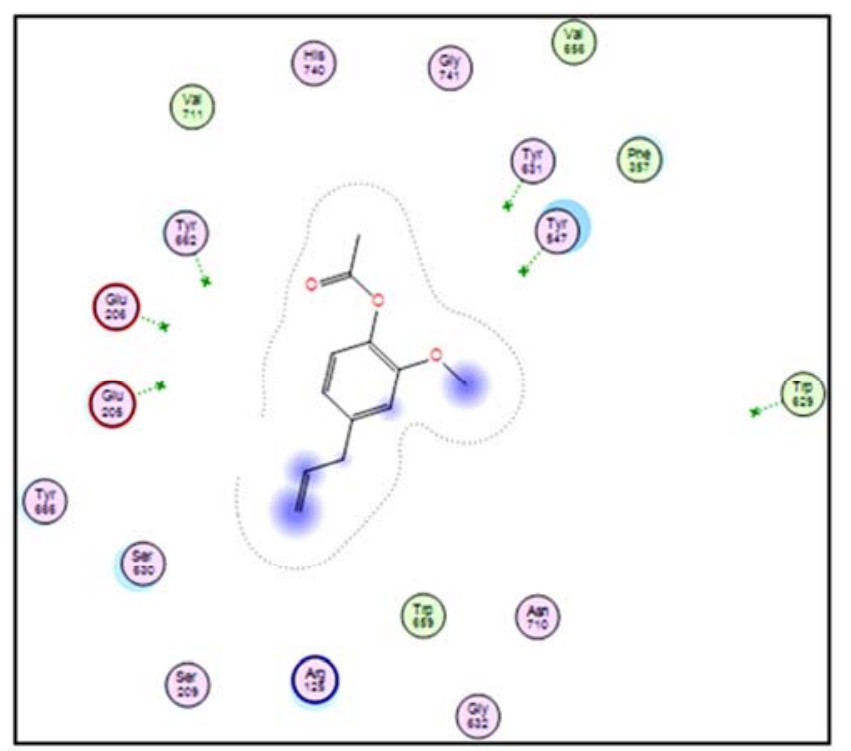

2D

Figure 3. Diagram interaction between enzyme and Acetyleugenol.

Given Results in Table 1 show balance interaction forces between ligands and enzyme. Our purpose is to identify the ligand which interacts with enzyme DDP-4 to allow best inhibition. 2D molecular method of the screen has been attributed to the MOE (Molecular Operating Environment) software, which is designed to visualize the active sites of the complex (protein-ligand). The ligand is prepared and made with an improved 2D depiction layout algorithm, and protein residues version are arranged around it to indicate links spatial proximity [28].

Acetyleugenol gives the most stable complex (Figure 3) with the lowest energy of $(-5.1175704 \mathrm{kcal} / \mathrm{mol})$. The second stable complex is formed with Eugenol (-4.69787455 $\mathrm{Kcal} / \mathrm{mol})$. The third stable complexe is formed with alphahumulen $(-4.59825325 \mathrm{kcal} / \mathrm{mol})$. Beta-caryophyllene gives complex with energy equal to $(-4.56311417 \mathrm{Kcal} / \mathrm{mol})$. In our study we will not discuss the complex obtained by Caryphyllene oxide (epoxyde) because it is toxic element. In complex formed with Acetyl eugenol there is only Van der Wals forces interactions.

\section{Conclusion}

In this work we presented the study inhibition of DPP-4 enzyme by main chemical constituents of clove using molecular mechanic, molecular dynamics and molecular docking (MOE software). According to the obtained results we conclude that among different chemical compounds of clove, Acetyleugenol is the best inhibitor of Dipeptidylpeptidase (DPP-4) and via this constituent clove, contribute to hypoglycemic effect. For further work, it will be interesting to study inhibition of DPP4 by other chemical compounds contained in different part of clove plant (root, flowers, barks...).

\section{References}

[1] H. J. Sohilait, "Chemical Composition of the Essential Oils in Eugenia caryophylata, Thunb from Amboina Island," Science Journal of Chemistry, 2015, 95-99. DOI: 10.11648/j.sjc.20150306.13

[2] G. P. Kamatou, I. Vermaak, A. M. Viljoen, "Eugenol-from the remote Maluku Islands to the international market place: a review of a remarkable and versatile molecule". Molecules, 2012, 6953-6981. DOI: 10.3390/molecules 17066953.

[3] R. K. Pundir, P. R. Jain, C. H. Sharma, Antimicrobial activity of ethanolic extracts of Syzigium aromaticum and Allium sativum Against food associated bacteria and fungi, Ethnobotanical Leaflets, 14, 2010, 344-360.

[4] K. N. Humini, R. Hamdane, R. Boutoutaou, M. Kihal, J. E. Henni, "Antifungal activity of clove (Syzigium aromaticum L) essential oil against phytopathogenic fungi of tomato (Solanum lycopersicum L.) in Algeria," J. Exp. Bio. and Agric. Sci, 2014, 2 (5): 447-454.

[5] M. J. Park, K. S. Gwak, I. Yang, W. S. Choi, H. J. Jo, J. W. Chang, E. B. Jeung, I. G. Choi, "Antifungal activities of the essential oils in Syzigium aromaticum (L.) Merr. Et Perry and Leptospermum patersoii Bailey and their constituents against various dermatophytes," J. Microbio, 2007, 45 (5): 460-465.

[6] L. Yazdanpanah, N. Mohamadi, "Antifungal activity of the clove essential oil Syzigium aromaticum on Paecilomyces variotii agent of pistachio dieback," J. Bio. \& Env. Sci, 2014, 42-45.

[7] M. M. Abozid, S. M. El-Sayed, “Antioxidant and protective effect of clove extracts and clove essential oil on hydrogen peroxide treated rats," Int. J. chem. Tech. Res, 2013, 1477-1485.

[8] L. Jirovetz, G. Buchbauer, I. Stoilova, A. Stoyanova, E. Schmidt, "Chemical composition and antioxidant properties of clove leaf essential oil," J. Agric. Food chem, 2006, 54, 63036307. DOI: $10.1021 / \mathrm{jf060608c}$.

[9] M. I. Nassar, A. H. Gaara, A. H. El-Ghorab, A. R. H. Farrag, H. Shen, E. Huq, T. J. Mabry, " Chemical constituents of clove (Syzigium aromaticum), Fam. Myrtaceae and their antioxidant activity,” Rev. Latinoamer. Quim, 2007, 47-57.

[10] K. Chaieb, H. Hajlaoui, T. Zmantar, A. B. Kahla-Nakbi, M. Rouambhia, Mahdouani K, Bakhroul A, "The chemical composition and biological Activity of clove essential oil, Eugenia caryophyllata (Syzigium aromaticum L. Myrtaceae): A short review," Phytother. Res, 2007, 501-506. DOI: $10.1002 /$ ptr.2124.

[11] D. F. Cortes-Rojas, C. R. Ferandes de Souza, W. Pereira Olivera, "Clove (Syzigium aromaticum): A Precious spice," Asian Pac. J. Trop. Biomed, 2014, 90-96.

[12] G. P. Kamatou, I. Vermaak, A. M. Viljoen, "Eugenol- From the remote Maluku Islands to the international market place: A review of a remarkable and versatile molecule," Molecules, 2012, 6953-6981.

[13] M. Saeed, M. Nadeem, M. R. Khan, M. A. Shabbir, A. Shehzad, A. M. Amir, "Antimicrobial activity of Syzigium aromaticum extracts against food spoilage bacteria," Glob. J. Med. Microbiol. Rev, 2013, 27-35. 
[14] H. K. Alma, M. Ertas, S. Nitz, H. Kollmannsberger, "Chemical composition and content of essential oil from the bud of cultivated Turkish clove (Syzigium aromaticum L.)," BioResources, 2007, 265-269.

[15] A. Ozturk, H. Ozbek, "The Anti-inflammatory activity of Eugenia caryophyllata essential oil: An animal model of antiinflammatory activity,” Eur. J. Gen. Med, 2005, 159-163.

[16] A. Slama-Chaudhry, M. Mavromati, A. Golay, Diabète de type II. - HUG - (Hôpitaux universitaires de Genève) Service de médecine de premier recours - DMCPRU, 2013, 29.

[17] A. Grimaldi, J. Cosserat, C. Breton, P. Cathébras, Les pathologies dites fonctionnelles, Elsevier, 2004, 162.

[18] A. Grimaldi, La santé écartelée - Entre santé publique et business, Dialogues, 2013, 220.

[19] M. R. Nangle, T. M. Gibson, M. A. Cotter, N. E. Cameron, "Effects of eugenol on nerve and vascular dysfunction in streptozotocin-diabetic rats," Planta Medica, 2006, 494-500. DOI: $10.1055 / \mathrm{s}-2005-916262$.

[20] S. Rajamani, R. Suganthi, M. K. Ravichandran, C. V. Anuradha, "Food seasoning spices mixture improves glucose metabolism and lipid profile in fructose-fed hyperinsulinemic rats," Journal Medicinal Food, 2005, 502-507. DOI: 10.1089/jmf.2005.8.502.

[21] R. Suganthi, S. Rajamani, M. K. Ravichandran, C. V. Anuradha, "Effect of food seasoning spices mixture on biomarkers of oxidative stress in tissues of fructose-fed insulin-resistant rats," Journal Medicinal Food, 2007, 149153. DOI: $10.1089 /$ jmf.2005.058.
[22] R. P. Dearlove, P. Greenspan, D. K. Hartle, R. B. Swanson, J. L. Hargrove, "Inhibition of protein glycation by extracts of culinary herbs and spices," Journal Medicinal Food, 2008, 275-281. DOI: 10.1089/jmf.2007.536.

[23] C. L. Broadhurst, M. M. Polansky, R. A. Anderson, "Insulinlike biological activity of culinary and medicinal plant aqueous extracts in-vitro," Journal Agriculture Food Chemistry, 2000, 849-852.

[24] R. Shukri, S. Mohamed, N. M. Mustapha, "Cloves protect the heart, liver and lens of diabetic rats," Food Chemistry, 2010, 1116-1121. Doi: dx.doi.org/10.1016/j.foodchem.2010.03.094.

[25] D. Röhrborn, N. Wronkowitz, J. Eckel, DPP4 in diabetes, Front. Immunol, 2015, Doi:

dx.doi.org/10.3389/fimmu.2015.00386.

[26] M. S. De Oliveira, W. A. Da Costa, D. S. Pereira, J. R. S. B. Botelho, T. O. De Alencar Mnezes, E. H. De Aguiar Andrade, M. S. H. Da Silva, A. P. Da Silva Sousa Filho, R. N. De Carvalho Junior, "Chemical Composition and Phytotoxic Activity of Clove (Syzygium aromaticum) Essential Oil Obtained with Supercritical CO2," J. of Supercritical Fluids, 2016, 185-193. Doi: dx.doi.org/doi: 10.1016/j.supflu.2016.08.010.

[27] Molecular Operating Environment (MOE), Chemical Computing Group, Montreal, Quebec, 2013 Canada.

[28] P. Labute, C. Williams, M. Feher, E. Sourial, J. M. Schmidt, Flexible alignment of small molecules, J. Med. Chem, 2001, 1483-1490. Doi: 10.1021/jm0002634. 